\title{
Model of KIBS Embedding Driving Enterprises' Technology Innovation Among Agricultural Industrial Clusters
}

\author{
Chen Jun \\ School of Business and Tourism Administration \\ Yunnan University \\ Kunming, China \\ chenjun_ydkm@126.com \\ Lu Qicheng* \\ 1.Business School \\ Ningbo University
}

\author{
Ningbo, China; \\ 2. Business School \\ Yunnan University of Finance and Economics \\ Kunming, China \\ 317404322@qq.com \\ Jing Hao \\ Business School \\ Yunnan University of Finance and Economics \\ Kunming, China \\ 977230882@qq.com
}

\begin{abstract}
In the Belt and Road strategy, innovation is very important for Chinese agricultural enterprises going out. KIBS Embedding, playing the role of intermediary, has been influencing the current innovation of cluster enterprises by its interaction with these entities. However, the existing research on KIBS embeddedness into industrial clusters focuses on that of manufacturing industry rather than agricultural industry. Therefore, the authors try to construct the model of KIBS embeddedness influencing the technology innovation among the agricultural industrial cluster, based on the concept model of complementary effects by industrial cluster and strategic alliance network to enterprises' technology innovation.
\end{abstract}

Keywords-KIBS embeddedness; agricultural industrial cluster; technology innovation; effect model

\section{INTRODUCTION}

The Belt and Road initiative provides the valuable opportunity for our country's agricultural cooperation with overseas countries. There exist rich agricultural resources and markets in areas along the Belt and Road regions. Especially the south and southeast Asia, being an early agricultural cooperator with China, occupies a significant place on the world stage. However, Chinese foreign agricultural cooperation is still underdeveloped owing to the weak technology innovation capability of our agricultural enterprises, which is shown by two following facts. Firstly, those going-out agricultural enterprises not only started late with small scale and short of professionals, but also developed stagnantly. Secondly, China has lunched few agricultural cooperation and communication programs with developed countries or multinational companies overseas, reaching unsatisfactory effects of technology demonstration and generalization [1]

KIBS has been an inevitability for the enhancement of enterprise technology innovation capability considering its critical role in activities as new product creation, new technique devising and their commercialization. That is to say, the scale and direction of enterprise technology innovation capability could be wheeled by professional knowledge services [2]. Domestic research on effects of KIBS embedding to enterprise technology innovation capability heavily aims at topics such as technology innovation performance, technology innovation efficiency, technology spillover and complementary innovation, and objects such as small-and-medium-sized private manufacturing enterprises, ordinary manufacturing enterprises, retail sales, High-tech SMEs [3-6]. However, rare achievements can be seen on the effects of KIBS embeddedness to enterprise technology innovation among agricultural industrial clusters.

KIBS embedding into agricultural industrial clusters has been viewed as an important pattern to strengthen the technology innovation capability of agricultural enterprises, which depends heavily on demands of their counterparts and customers together with the connection with relative universities and research institutes [7]. KIBS embedding into industrial clusters could drive the transformation of their network structure, and further increase their knowledge accumulation of various subjects. On the one hand, the transformation of network structure would enhance the knowledge spillover and the absorptive capability among agricultural industrial clusters members. On the other hand, the enhancement of absorptive capability would intensify knowledge spillover. Both of the two capabilities are positively relevant to technology innovation of agricultural enterprises [8]. However, when studying the effects of KIBS embeddedness to the enterprise technology innovation among agricultural industrial clusters, domestic scholars have paid more attention to the role of network structural transformation than to that of other factors among industrial cluster, and also more to the effects of KIBS to the result of the enterprise technology innovation than to its process.

\footnotetext{
* Corresponding author
} 
Therefore, it is of great practical importance for our country's agricultural cooperation with overseas countries, if we try to study the topic of KIBS embedding into agricultural industrial clusters which will make positive influences to the technology innovation process and innovation capability of agricultural enterprises.

\section{CHARACTERISTICS OF AGRICULTURAL INDUSTRIAL CLUSTERS AND THEIR ENTERPRISES TECHNOLOGY INNOVATION}

\section{A. Characteristics of Agricultural Industrial Clusters}

Many industrial clusters belong to the handicraft industry and the manufacturing industry other than the agricultural industry because of its characteristics such as long production cycle, decentralized production base, low degree of specialization and short industrial chain [9]. Domestic and overseas typical case study have come to the conclusion that agricultural industrial clusters not only share some characteristic with ordinary clusters, but also specialize by its distinguishing features, including that the natural resource endowments constitute the material foundation of agricultural industrial clusters, the agricultural industrial cluster is featured by evident regional cultural rootedness, the guiding role of agricultural specialty cooperatives or leading enterprises provides the organizational foundation for the evolvement of industrial clusters, and the government also plays the guiding role in this process [10]. Moreover, the experience of agricultural industrial clusters in developed countries has demonstrated that the technology innovation can definitely drive the development of agricultural industrial clusters, and is a critical factor of maintaining the competitiveness in international agricultural markets [11].

\section{B. The Characteristics of Technology Innovation Knowledge for Agricultural Enterprises}

The knowledge necessary for cluster enterprises to conduct technology innovation activities should be specialized because of the characteristic of the agricultural industrial cluster. Firstly, the government must provide public knowledge service. Secondly, agricultural enterprises must build "industry university research cooperation strategic alliance", so as to better provide specialized knowledge service. Thirdly, the knowledge spillover effects should be strengthened between leading enterprises and nearby counterparts. Fourthly, agricultural technology institutions and cooperatives should provide public affiliated service for their enterprises. Fifthly, the social relationship network should be formed based on the "blood, genetic and geopolitical relations, so that the cluster enterprises could share knowledge by this kind of social complementary mechanism. Obviously, the governmental sectors, scientific service institutions, the strategic alliance, technology and cooperative institutions and social relationship network are all important resources of technology innovation knowledge for agricultural enterprises.

\section{THE RELATIONS BETWEEN KIBS EMBEDDEDNESS AND THE ENTERPRISE TECHNOLOGY INNOVATION AMONG CERTAIN INDUSTRIAL CLUSTER}

Gnyawali and Srivastava put forward the complementary effect model for cluster and alliance network to enterprise innovation, and thus demonstrated the effects from multiple cluster and network factors to favorable conditions and barrios in the process of enterprise innovation [12]. Fatimasenghore et. al. employed this model to empirically test the innovation success probability of NASA International Space Application Challenge Project, in which the authors analyzed the influences of innovation promotion and inhibition factors to the project's innovation process and resulting success, and theoretically revealed the dynamic mechanism of innovation process to its results [13]. Unfortunately, this model has not been testified in the enterprise innovation of agricultural industrial clusters. The effects of KIBS embedding into agricultural industrial cluster to its enterprise technology innovation process should be distinctive form that of the ordinary manufacturing industry because of the uniqueness of its characteristics and its technology innovation knowledge resource.

\section{A. The Complementary Effect Model of Cluster and Strategic Alliance Network to Enterprise Technology Innovation}

The cluster factors could reduce the innovation uncertainty by influencing the entrepreneur consciousness and motives. The intensive competition among enterprises of certain cluster could intensify the entrepreneur consciousness of developing new technology and their motives of conducting innovative activities. Moreover, the high social complementarity of enterprises in certain cluster would be better for revealing the general knowledge and ideas of the specialists in this cluster, so as to reduce the innovation uncertainty. The cluster dynamic could effectively benefit for increasing innovation profit by intensifying the competition and social complementarity. The effect of strategic alliance network to technology innovation originates from the formal mechanism of enterprises' resources circulation, while the enterprise resource potential would furtherly heighten the probability of technology innovation by reducing the resource restriction and overcoming the organizational rigidity. Thus various enterprise strategic alliance network guiding patterns (merger-oriented and alliance-oriented) would have different network influences to the enterprise innovation achievements.

\section{B. Effects of KIBS Embeddedness to the Industrial Cluster and its Kernel Enterprises}

1) The Effects of KIBS Embeddedness to the Industrial Cluster

Since KIBS is embedded into the industrial cluster, KIBS organizations would create formal and informal connections with enterprises of this cluster, which could help to introduce new comers and create new knowledge, realize knowledge proliferation, increase the knowledge amount and categories, and enhance the potential knowledge spillover. KIBS could provide external knowledge for those kernel enterprises among the cluster, thus would strengthen the network knowledge resource potential of cluster enterprises, and release the resource restrictions for kernel enterprise innovation. With 
KIBS embeddedness, the kernel enterprise network alliance could introduce new comers which not only enlarge the scope of kernel enterprise alliance and eliminate some alliance relations of low efficiency, but also stimulate network dynamics.

\section{2) The Effects of KIBS Embeddedness to the Kernel} Enterprises

KIBS enterprises could integrate the new knowledge obtained from entrepreneur teams, external private enterprises, public R\&D bases, easily accessible resources, competitors and client-enterprises, and then proliferate it into enterprises of the cluster by various transmission channels. KIBS enterprises would also realize knowledge proliferation by establishing formal or informal internal relationships with each other, among which the former includes long-term competitive and cooperative connection, short-term contract relation, goods selling connection, and so on, and the latter mainly consists of the private communication of among employees in both KIBS enterprises and client-enterprises, as well as the staff mobility of KIBS enterprises.

\section{THE EFFect Model of KIBS EMBEDDEDNESS TO ENTERPRISE TECHNOLOGY INNOVATION OF AGRICULTURAL INDUSTRIAL CLUSTERS}

Currently, research on the role of KIBS to enterprise mergers has been rarely seen, and the topics on agricultural mergers focuses more on foreign-funded mergers, overseas mergers and regional mergers with the target of ordinary agricultural enterprises rather than KIBS ones [14-16]. Owing to its short development history, a great deal of Chinese agricultural industrial clusters did not include KIBS enterprises, leading to the result of weak knowledge foundation and poor innovation capability in these clusters. For lots of agricultural industrial clusters, their agricultural enterprise have been established cooperative relationships with scientific and research institutes relying on specific governmental polices, by which the product joint development could be conducted and the knowledge foundation and innovation capability of these clusters like Shouguang Vegetable Industrial Cluster of Shandong Province and Yunnan Flower Industrial Cluster be strengthened. By embedding KIBS into agricultural industrial clusters, new knowledge could be absorbed and applied into external enterprises to enhance cluster and network dynamics. We will theoretically model the effect of KIBS embeddedness to technology innovation of agricultural industrial clusters(See Figure1).

\section{A. The Effects of KIBS Embeddedness to the Competition with the Cluster}

Relying on its role of intermediary, KIBS would help enterprises to acquire, produce and transform knowledge, and introduce the external knowledge, thus the kernel enterprises could keep watch on other counterparts within the same region. Furtherly, kernel enterprises would strengthen their innovation consciousness and motives so that the competition could be intensified, even would produce knowledge spillover by establishing informal relationships with affiliated counterparts. Moreover, the fragmented knowledge spillover would hasten the birth of more innovative projects and increase the successful probability.

\section{B. The Effects of KIBS Embeddedness to Social Interaction}

When guiding client-enterprises to make innovation products, KIBS embeddedness into industrial cluster would play its long-term complementary role with the enterprises, thus creating sound private relations as well as the staff mobility between KIBS enterprise and its client-enterprises, by which knowledge sharing and transformation would be realized and the cluster socialized complementarity would be testified.

\section{The Effects of KIBS Embeddedness to Network Resource Potential}

With KIBS embedding into the industrial cluster, its enterprises would establish formal economic relationships with kernel enterprises, while the latter could conduct innovation activities by absorbing new external knowledge, which would benefit for accumulating and diversifying the existing knowledge in the cluster. Moreover, KIBS would help kernel enterprises to introduce new knowledge to innovation activities, so as to release the resource limitation. And also the introduction of new ideas would be able to optimize the organization rigidity in kernel enterprise innovation, initiate more innovative projects and attract other counterparts joining the kernel enterprise alliance, so as to strengthen the potential of network resources.

\section{The Effects of KIBS Embeddedness to Joint Development Guiding}

If KIBS is embedded into the industrial cluster and guide the innovative activities, the kernel enterprises would establish formal cooperative relationships with KIBS institution, jointly develop new products and technology and solve the problems during these processes, so as to make more innovative

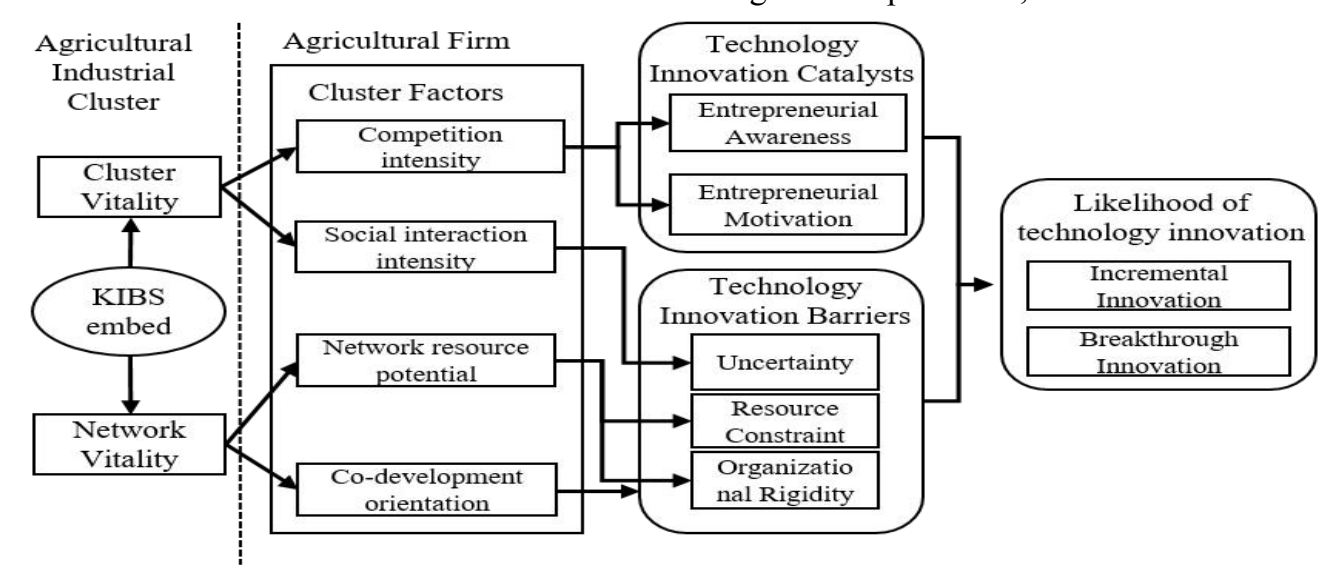

Fig. 1. The effect model of KIBS embeddedness to enterprise technology innovation among agricultural industrial clusters. 
breakthroughs.

\section{CONCLUSIONS}

Technology innovation of agricultural enterprises has an important role in the development of agricultural industrial clusters. The introduction of external innovation is an important way to promote the technological innovation of agricultural enterprises in clusters. Combining the uniqueness of the agricultural industrial cluster, the effect model of KIBS embedded in the agricultural industrial cluster on enterprise technological innovation was built based on the conceptual model of Gnyawali and Srivastava. There are significant conclusions as follows:

- $\quad$ KIBS embedding agriculture industrial clusters erects bridge for agricultural enterprises' innovation, achieves the production and transfer of knowledge, improves the cluster vitality, and strengthens the competition and social interaction intensity among enterprises in clusters. Thereby, it improves the entrepreneurial innovation consciousness and motivation, reduces the uncertainty in the innovation process, and raises the success possibility of the enterprise technology innovation.

- $\quad$ KIBS embedding agriculture industrial clusters brings out the external knowledge sources, so improves the network vitality, enhances the enterprises' potential of using network resources, reduces the innovation resource constraints, overcomes the organizational rigidity, and makes KIBS organizations jointly develop new technologies and products with agricultural enterprises. Thus these organizations could share the innovation knowledge, reduce the risk of $\mathrm{R} \& \mathrm{D}$, and raise the success possibility of their technological innovation.

The effect model is only constructed through the theoretical induction. It is also lack of empirical research on the magnitude of relationships among industry cluster factors, technological innovation process and the possibility of technological innovation.

\section{ACKNOWLEDGMENT}

The paper is supported by the National Natural Science Foundation of China (No.71362014), China Postdoctoral Science Foundation Funded Project(No.2015M570494), and Natural Science Foundation of Yunnan(No. 2014FB146). The authors thank other members of the research group for helpful, valuable, and constructive comments and suggestions on earlier versions of this paper.

\section{REFERENCES}

[1] S.S. Song, "The Expansion of Foreign Agricultural Cooperation in the Belt and Road Initiative Strategy," Journal of International Economic Cooperation, pp. 63-66, September 2014.

[2] S.W. Li, Y.T. Chen, C.L. Si, and B.H. Peng, "An Analysis of Formation and Evolution of Enterprise Technological Innovation Capability based on KIBS," Journal of Systems and Management, vol. 20, pp. 421-427, August 2011.

[3] X. Zhu, and Z.N. Lu, "Research on Affection of the KIBS Enterprises Embedding Strength to the Technology Innovation Performance of Technology-based Small and Micro Businesses," Science\&Technology Progress and Policy, vol. 31, pp. 142-146, May 2014.

[4] X. Shi, J. Hong, and D.T. Zhao, "Impacts of KIBS on Two-stage Innovation Efficiency of High-tech Industry," China Science and Technology Forum, pp. 43-49, January 2013.

[5] Z. Pei, and Y.S. Gao, "KIBS and the Innovation of Industrial Clusteran Analysis Perspective Based on Technology Spillover," Economic Survey, vol. 26, pp. 31-34, May 2009.

[6] Q.L. Fan, Y.F. Shao, and X.W. Tang, "Spontaneous Evolution of Interactive Innovation between Knowledge-Intensive Services and Cluster Manufacturing Enterprises," Science of Science and Management of S.\&T, vol. 33, pp. 147-155, April 2012.

[7] E.L. Li, Y.W. Shi, and X.J. Li, "The Structure Analysis of Agricultural Innovation System Based on Agricultural Cluster: A Case Study of Flower and Plant Industrial Cluster in Yanling County, Henan Province," Economic Geography, vol. 32, pp. 113-119, November 2012.

[8] Y.R. Wang, "A Research on the Factors of Agricultural Technology Innovation on the Perspective of Agriculture Cluster," Economic Survey, vol. 29, pp. 38-42, September 2012.

[9] P.D. Zhou, and Q. Sun, "Discussion on Some Problems of the Development of Agricultural industrial clusters," Guizhou Social Sciences, pp. 80-83, August 2012.

[10] P. Lu, and X.H. Chen, "Concept Analysis,Evolution Characteristics and Development Strategies of Agricultural Industrial Clusters," Research of Agricultural Modernization, vol. 36, pp. 575-579, July 2015.

[11] F.J. Huang, and Z.G. Gao, "Development Experience of Agricultural industrial clusters in Developed Countries and the Path Choice of China," Journal of Commercial Economics, pp. 133-135, August 2015.

[12] D.R. Gnyawali, and M.K. Srivastava, "Complementary effects of clusters and networks on firm innovation: a conceptual model," Journal of Engineering \& Technology Management, vol. 30, pp. 1-20, January 2013.

[13] F. Senghore, E. Campos-Nanez, P. Fomin, and J.S. Wasek, "Using social network analysis to investigate the potential of innovation networks: lessons learned from nasa's international space apps challenge," Procedia Computer Science, vol. 28, pp. 380-388, March 2014.

[14] Y. Xu, "A Comparative Study on the Antitrust Legislation of the Domestic Agricultural Enterprises in the Foreign Capital Acquisition between Japan and USA," World Agriculture, pp. 27-31, March 2016.

[15] J.Y. Wang, and L.J. Zeng, "Foreign Capital Merger and Acquisition and Safety Guarantee Measures of China's Agricultural Products," Rural Economy, pp. 24-29, October 2015.

[16] Q.L. Lu, Q.G. Lan, and Z.J. Hou, "Research on the Behavior of Agricultural Enterprises Merger and Acquisition based on the Region," Issues in Agricultural Economy, vol. 29, pp. 86-89, April 2008. 